\title{
Strategies for preserving memes as artefacts of digital culture
}

\author{
Fátima García López \\ fatimag@bib.uc3m.es \\ Sara Martínez Cardama \\ Smarti1@bib.uc3m.es \\ Universidad Carlos III de Madrid, Spain
}

\begin{abstract}
The internet archives kept by heritage libraries are analysed, focusing specifically on that new type of expression characteristic of web culture and digital folklore, the meme. Five paradigmatic examples of heritage institutions engaging in web archive initiatives are explored: the Library of Congress, British Library, Bibliothèque Nationale de France, Biblioteca Nacional de España and National Library of Australia. Specific assessment categories are defined for the study. The findings reveal a lack of collection policies for such representative objects of today's mass culture and identify the challenges both for the custodying institutions and for research in the future.
\end{abstract}

Keywords: memes, ephemera, web archiving, heritage libraries, preservation, digital culture

\section{Introduction}

The memes, gifs and tweets circulating across social networks portray today's population in terms of how we conduct our interpersonal relationships, consume information and interpret the surrounding world. Whilst possibly deemed as trivial or insignificant today, these expressions may prove to be of cultural and historic value for future generations. Although a number of definitions of these cultural objects have been put forward, they may be deemed as patterns of information conveyed from person to person that shape the mindsets and behaviours of a given social group (Knobel, Lankshear, 2007).

Such objects may form part of what has traditionally been known in heritage preservation as ephemera, documents generated around an event or article of current interest with no intention of outliving the topicality of their message (Pemberton, 1971).

They have traditionally consisted in printed matter (trading cards, invitations, post cards, posters, bills, brochures, advertisements, labels, stickers, badges and the like) used to explore past behaviour and practice. The media supporting materials of such sociological and iconographic significance has now veered toward the virtual, with the internet as the primary channel for their dissemination. That circumstance renders these expressions the more ephemeral.

Memes' heritage value is also associated with expressions of born-digital pop culture or folklore (Tangherlini, 2016). Collection, archiving, description and analysis methods must therefore be 
established to accommodate that connection. The speed and virality of networked communication across social media encumber such tasks, posing a challenge for the institutions entrusted with the preservation of our new pop culture.

Most studies on memes highlight their cultural potential (Dawkins, 1976; Shifman, 2014) and social and communication power (García-Avilés, Robles, 2016) against a backdrop of social critique and the narratives authored by new political movements (Moody-Ramírez and Church, 2019; Martínez Rolán and Piñeiro-Otero, 2016). Very few papers analyse their heritage value, however. This article reflects on the necessary preservation of memes as digital objects, bearing in mind that they will eventually form part of today's social history without which certain contemporary political and social events would be incomprehensible.

The volatility of digital information is beginning to have a social impact and attract media attention. In 2015 Vinton Cerf, Google Vice President and one of the fathers of the internet, warned that recent digital generations' creations may practically disappear, for Homo digitalis consumes information in ways that thwart preservation of that material for the future. The term 'digital dark age' has been coined to describe the void created by the loss of digital information. Just as 'digital archaeology' aims to preserve software and hardware, other content-related initiatives have been launched to prevent a digital blackout. Work in that direction is underway at institutions such as national libraries, for as their primary aim is to conserve their countries' cultural acquis, they have been implementing web archive strategies for some time to preserve and ensure access to websites of special significance bearing the extension indicative of the national domain. Such institutions have recently realised that the website is no longer the basic unit of today's digital expressions, for given the de-fragmented nature of internet content, other forms of expression (tweets, posts and memes) have acquired equal significance for today's collective memory.

This article explores the state-of-play of internet heritage indexing and more specifically of meme archiving. Five paradigmatic examples of heritage institutions that have been engaging in web archive initiatives for some time are studied: the Library of Congress, British Library, Bibliothèque Nationale de France, Biblioteca Nacional de España and National Library of Australia.

Their plans for digital archiving are used to define assessment criteria on the inclusion, processing and significance of memes as a cultural object meriting preservation. The study identifies the challenges still outstanding to satisfactorily preserve these digital artefacts and launches a debate on whether such digital, viral expressions should form part of social and collective memory and included in duly curated collections to afford future generations a precise understanding of online pop culture.

\section{Literature review}

Two major themes arise around the object of this study: the significance of memes as digital culture artefacts and the web preservation initiatives in place, particularly those geared to these ephemera.

\section{- Memes as digital culture artefacts}

The word meme, derived from the Greek mimema (that which is imitated), was coined by Dawkins (1976), who analogised from genetics to describe the conveyance from one generation to the next, via imitation, of cultural elements such as phrases, behaviours or pop music. 
Shifman (2012) reformulated the term for adaptation to today's digital culture, contending that unlike the stable, lasting cultural units identified by Dawkins, the content now at issue is shortlived, quickly gaining and as quickly losing online popularity. Such artefacts can be discussed, shared and re-contextualised but, in that author's opinion, must be treated as groups of content units rather than stable cultural units.

Shifman (2013) also recognised the complexity of meme definition and structure, which indisputably affects preservation. She characterised these artefacts in terms of three attributes: ambiguity and diffusivity; reproduction through imitation; and adherence to the rules of competitive selection. The third element is vital to deeming memes an element of participatory culture, for internauts actively search for them and define their context.

Whilst virality is essential to meme dissemination, without user re-contextualisation the conceit as it is understood today would lack meaning. From that perspective, as they are not merely consumed but discovered, memes lie within Jenkins's (2003) transmedia vision that has had such an impact on digital story creation and communication. Assuming that the origin of most internet artefacts lies in transmediation, in memes two such events can be defined: one at the origin and the other during dissemination. Origin transmediation entails the re-appropriation and re-contextualisation of an image drawn from other media. Dissemination transmediation stems from the possibility of circulating the object with shared meaning across different media.

That also connects into to the first attribute, for on the individual (micro) scale memes are diffuse elements that call for a social macrostructure to acquire significance. Such circumstances, conceptualised as attitudinal by Shifman (2013), who distinguished them from meme form and content, would reveal their author's position respecting the information, message and context portrayed. The participatory structure underlying memes would consequently have implications for their preservation from the standpoint of digital continuity, for memes cannot be preserved as isolated digital objects devoid of the context that affords them full meaning.

Their complexity stems from their infinite structure in which recipients can add new layers with different meanings for other uses and contexts (Nichols, 2018). The participatory and social entitlement to use such visual objects informs the determination of their specific meaning and how that meaning may be decoded and adapted by recipients, drawing from their expressive and communicational aptitudes.

Further to Shifman (2012), like gifs, memes entail creative parody or mash up techniques consisting in imitating, repeating or mixing cultural and social constructs previously in place. Despite their apparent simplicity, memes involve creativity and social innovation that affect networked communication and read-write strategies. They are non-trivial elements for research designed to identify social or individual voices in a specific space-time (Shifman, 2014). Despite their humour and triviality, they are more than mere pastimes or entertainment, forming part of 'post-modern folklore'. Authors such as McGowan (undated) classify them as 'digitally born folklore' in light of their ubiquity, in which circulation and production exceed mere virality. Their structure may itself be deemed as a genre apt for use as an interpretive source for research. Shifman (2013) identified a divide between mimetics as academic conceit and its meaning for today's web uses in (digital) vernacular language.

A number of features of memes' social and communicational power can be defined: the first and most visible is their humoristic aspirations, the immediate aim being to enable recipients to relativise everyday events. Another is their ability to synthesise, for reducing the meaning of an idea to its minimum expression favours the speed and efficacy of communication. A single image may allude to a trivial or insignificant event in a complex social context, generating very eloquent micro-narratives with a sparsity of elements (González and González, 2013). Milner (2012) 
observed that composing such microstories calls for a certain mastery to turn language into a shared lingua franca. It also entails a strict command of everyday situations and recognisable archetypes.

In addition to the foregoing, the most characteristic feature of memes may be their nondurability. To paraphrase Bauman, their status as digital ephemera derives from their liquid modernity.

\section{- Memes: a new type of ephemera}

Ephemera is the plural of the Greek word ephemeron, from epi (on, around) and hemera (day). The term was initially used in natural science to designate short-lived flowers or insects. In information and documentation spheres, it was first coined in 1962 by John Lewis in his Printed Ephemera, which spawned further studies on the subject.

Pemberton (1971) defined ephemera to consist in documents generated around a given event or article of current interest not intended to outlive the topicality of their message. The Dictionary of Art (Turner, 1996) nuanced that definition by stressing the transitory nature of these trifling documents of everyday life, in which the author included greeting cards, invoice letterheads, bills, business cards, political brochures, advertisements, pop music, prospectuses, ex libris, stationery letterheads, theatre and concert invitations, theatre tickets, prayer cards, labels and packaging.

In today's digital context the conceit now poses other delimitation issues, for many artefacts circulating across the internet could be classified as ephemera. As most of those documents, like memes and gifs, are anonymous and closely associated with the context in which they are created, the term may be redefined to include those two latter artefacts.

The value of such digital objects as a source of primary information for researchers in the future poses challenges for their conservation and preservation. Just as nineteenth century candy wrappers, trading or dance cards furnish insight into how people inter-related in the past, memes may be deemed to afford a true and fair view of communication today. They may consequently be assumed to be coveted by future researchers studying this generation's interrelationships, its sense of humour and the impact of certain events disseminated in the traditional media (García-López and Martínez Cardama, 2019).

The officer in charge of the Spanish National Library's web archiving service, Pérez Morillo, accurately justified why such material should be archived, associating it with the institution's collection of physical ephemera and advocating for a heightened awareness of this type of expression in society at large and especially among information professionals:

II would like society as a whole to be aware that preserving this information, which mirrors our way of life today, is incumbent on us all. And librarians in particular, who traditionally tend to look backward, should realise that for researchers of the future to be able to explore their heritage, we need to preserve that heritage today, while it's still alive on the internet' (Gil, 2018).

The institutions and professionals entrusted with safeguarding today's collective memory would seem to have a clear mandate: this material should be preserved to prevent the so-called 'digital dark age' alluded to by a number of historians. Since the late nineteen nineties many professionals have been aware of the problems that such a digital blackout would pose for future generations.

One such visionary was Brewter Kahle, founder of Internet Archive, an initiative geared to preserving the volatile websites generated since the onset of the Worldwide Web in the mid nineteen nineties. That archive has become a digital repository for ephemeral media, today 
constituting a vast database with the following categories: websites, books and texts, audio, motion pictures (ephemeral cinema), photographs and software (Mayagoitia and González Aguilar, 2017).

Kahle's undertaking was followed by initiatives sponsored by heritage institutions such as national libraries and their web archiving programmes. Some of the most prominent include the programmes launched by the Library of Congress, National Library of Australia, British Library, Bibliothèque Nationale de France and Biblioteca Nacional de España, institutions taken as the reference framework for this study.

In most cases, their web archives have been built with web crawling techniques in which specific software identifies and archives the websites of certain domains of national interest (.gov, .es) in keeping with predefined parameters and timing. In that process, which may be automatic or selective, these institutions pursue maximum efficiency by only archiving sites not indexed by other national or regional entities.

The advent of social networks, in turn, has led to new approaches to social research in which the data circulating in those channels is understood as a source of historic information. Some authors have encouraged digital humanities researchers to preserve Twitter as a cultural artefact (Bruns and Weller, 2016).

The Library of Congress pioneered that practice, deeming the network to be an object of preservation and archiving all public tweets since 2006. Beginning in 2017, however, it has followed a more selective policy, conserving only those that may have historic significance. That change is due both to the impossibility of archiving the entire Twitter universe and in part to the rise in the proportion of images relative to text, for embedded audiovisual content poses problems for crawlers.

Although initiatives are in place to preserve tweets by hashtag or topic for research, such use is limited by the $1 \%$ restriction on collection imposed by public APIs. Individual archives can be downloaded, however, to form a personal historic archive for every account.

Web archives, whether of websites or data drawn from social networks, is in any event subject to a series of limitations that must not be ignored:

- technical: storage space needs

- legal: copyright, for instance, in third party content embedded in tweets

- economic: institutions' need to rationalise resources in the face of budgetary constraints

- digital content-related: vast production of ephemeral, multimedia (a format that may be lost during scraping) information.

In addition to such considerations, certain inherent characteristics of memes as ephemeral digital matter render their preservation in web archives even more difficult. Challenges posed in disciplines such as digital curation, including meme preservation throughout the life cycle of the object, for instance, remain unsolved. That has implications not only for preservation or archiving, but also for the capacity to generate added value for the creation of new sources of information and knowledge (Digital Preservation Coalition, 2009). The technological dimension is, then, only one of the elements for guaranteeing digital continuity, which entails more than the mechanical collection of and access to materials (Higgins, 2018). The digital curation of ephemeral contemporary objects such as memes calls for a holistic vision on the part of institutions when planning resources, complying with standards, deploying control mechanisms and verifying data. Libraries, archives and the officials responsible for institutional repositories are essential partners in that endeavour. 
Aware of the challenge posed by their conservation as part of digital memory, this study explores the following research questions.

$R Q .1$. Should memes be deemed a source of primary information for future researchers and consequently included in heritage institutions' digital preservation policies?

RQ2. How are some of the heritage majors archiving this ephemeral digital material?

$R Q 3$. How do they make these collections of cultural artefacts available to researchers?

\section{Methods}

This study aims primarily to know how this new type of documents known as memes is archived by institutions entrusted with the conservation and preservation of a country's documentary heritage. It also seeks to determine these institutions' handling of the new shared digital culture and their preservation and dissemination strategies.

To that end, five national libraries were analysed: the Library of Congress, National Library of Australia, British Library, Bibliothèque Nationale de France and Biblioteca Nacional de España. Those heritage institutions were chosen because they have long been collecting ephemera, including all manner of graphic and popular audiovisual materials. They have also made archiving world wide web objects a significant collection-building project. The choice of these five institutions therefore aimed to establish an overview of the models in place for preserving and disseminating the digital heritage and online popular culture (Table I).

Table I. National libraries studied

\begin{tabular}{|c|c|c|}
\hline Institution & Website & Web archive \\
\hline Library of Congress & https://www.loc.gov/ & $\begin{array}{l}\text { https://www.loc.gov/programs/we } \\
\text { b-archiving/about-this-program/ }\end{array}$ \\
\hline British Library & https://www.bl.uk/ & $\begin{array}{l}\text { https://www.bl.uk/collection- } \\
\text { guides/uk-web-archive }\end{array}$ \\
\hline $\begin{array}{ll}\text { National Library of } \\
\text { Australia }\end{array}$ & https://www.nla.gov.au/ & https://trove.nla.gov.au/website \\
\hline $\begin{array}{l}\text { Biblioteca Nacional de } \\
\text { España }\end{array}$ & http://www.bne.es/ & $\begin{array}{l}\text { http://www.bne.es/es/Colecciones } \\
\text { LArchivoWeb/ }\end{array}$ \\
\hline $\begin{array}{l}\text { Bibliothèque Nationale } \\
\text { de France }\end{array}$ & https://www.bnf.fr & $\begin{array}{l}\text { https://www.bnf.fr/fr/archives-de- } \\
\text { linternet\#bnf-contribuer }\end{array}$ \\
\hline
\end{tabular}

Inasmuch as the professional literature has not yet analysed the preservation of memes, the assessment categories used here were established specifically for this study. They were defined in keeping with trends set out in recent articles (McGowan, undated, for instance) in which memes are analysed and interpreted as elements of digital folklore in the framework of the American Folklife Center's Web Cultures Web Archive, a Library of Congress project. This article discusses the shortcomings still in place in the automatic archiving of such a complex type of material and underscores the need for research on building visual collections able to capture all its signifiers and meanings.

In that same vein, Tangherlini (2016) defined four areas of research for digital folklore materials: collecting and archiving; classifying, archiving and retrieving; visualising and browsing; and analysing. His study identified new criteria for collecting and archiving material deemed to constitute digital folklore to ensure consistency with the dynamic nature of the web. After 
scraping the web to collect the information, the author studied mechanisms for including such ephemeral digital objects in thematic collections, duly curated by experts and providing for dynamic retrieval.

On the grounds of the foregoing, the categories assessed here were as follows.

- Meme archiving to determine whether or not libraries deem memes to be a new digital document worthy of conservation.

- Selection and preservation policies to determine type of selection (mass or selective), periodicity and archiving levels in the wake of crawling or scraping.

- Collection building and access to determine the type of metadata and collections generated by institutions to add value to these objects and assess whether memes are deemed to be documentary units. The inclusion of these artefacts in thematic collections to illustrate a newsworthy political or social event was also analysed, along with user access to the materials with the libraries' search tools.

The study was conducted from a qualitative perspective, assessing the information furnished by the institutions themselves on their websites in terms of the aforementioned categories. As noted in the discussion of the results, shortcomings were identified in those data. The resulting absence of official information on some of the items analysed necessitated specific searches in the institutions' own collections to gather the most accurate information or resorting to indirect sources such as the media or informal networks.

\section{Results}

The results are set out below by the assessment categories explored.

\section{Meme archiving}

Given the specificity of memes as digital artefacts, institutions were not initially expected to regard them as a separate document type in their web archives. Further to information furnished informally by some libraries, however, memes do form part of their digital collections, either as material supplementary to other document types (websites, tweets) or as part of collections on specific topics (such as general elections or political protests).

Institutions do not generally reveal details on the archivist processes involved. Web archive policies focus on the websites of the domain of general interest for the country, without specifying the technical process applied to embedded digital objects. In some cases, programme leaders have mentioned meme archiving in statements released to the media (as in the case of the Spanish library). Other less formal sources of information that at times furnish clues in that regard include institutions' blogs (in Spain and US).

The sole library that provides detailed information in its catalogue is the Library of Congress, in the Web Cultures Web Archive collection maintained by its American Folklife Center, in which memes are deemed a type of document (Figure 1). Sites documenting memes (such as Cuánto Cabrón or Internet Meme Database) are specifically mentioned as collection items. User access, in turn, is ensured because 'meme' is included as a search and retrieval term in the collection's subject headings.

[insert Figure 1]

Figure 1. American Folklife Center's Web Cultures Web Archive collection (source: https://www.loc.gov/collections/web-cultures-web-archive/about-this-collection/) 
Whilst neither the British Library nor the National Library of Australia furnish detailed information, memes can be retrieved by searching their data catalogues. In the former, matches are retrieved tangentially only, when the word appears in Twitter streams or as hashtags. A similar procedure in the Australian library retrieves meme-generating websites that bearing the national domain.

The justification for archiving these micronarratives wielded by libraries furnishing such information is their comparability to physical ephemera. For the Library of Congress they constitute 'ephemeral social media', whilst the Biblioteca Nacional de España relates them directly to its traditional ephemera, contending that memes may have documentary value for future generations of researchers.

\section{Selection and preservation policies}

All the libraries analysed furnish information on their web archive preservation and selection policies on their websites (either as explicit collection policies or in specific blogs or FAQs). Although the criteria are not standardised but specific to each institution, certain common features were found:

- importance of the resource or information for the country at issue

- plurality, collecting documents from different perspectives and all manner of social media

- non-duplication of content, excluding sites archived by other public institutions

- collection building, sites of particular significance for the national history or culture (such as general elections or terrorist attacks)

- risk of website disappearance.

All institutions consistently include information on the type of site, primarily national or regional government websites not archived by any other institution. They also envisage the mass collection of websites with a specific domain (such as .uk or .au).

Collection building policies vary. In the United Kingdom for instance, the six libraries involved in handling legal deposit proceedings have constituted a partnership, the UKWA (United Kingdom Web Archive) for that purpose. In the PANDORA project in Australia, the national library partners with other cultural institutions. In all except the Biblioteca Nacional de España, users can propose websites they believe to be of interest or at risk of disappearing for inclusion in the archive.

The selection process is similar in all. Sites with the country domain are collected wholesale yearly using specific crawlers. Crawling is not confined to the country's own domains and subdomains, but also mines data from generic extensions (.com, .org) hosted in a national server or having an address on national soil. All the institutions analysed except the Library of Congress base their selection on legal deposit-related legislation, which provides for the conservation of websites associated with national domains. In keeping with such legislation, content in private networks and personal mails is excluded.

All the libraries also selectively collect sites of interest to the country, further to three criteria:

- matters of cultural or historic significance

- collections on important events

- particularly ephemeral and therefore vulnerable documents.

Satisfactory thematic collection building calls for human intervention, involving both librarians and outside specialists, to ensure consistency and significance for subsequent research. 
Particularly newsworthy events predominate in the selective collections which, along with collections of objects at greatest risk of disappearance (Wikipedia pages or social networks such as the now defunct 'Fotolog'), require more exhaustive processing by so-called 'web conservers'.

\section{Collection building and access}

The procedures followed to archive memes in collections were analysed under this category. That involved determining whether memes were deemed to be documentary units or to form part of broader thematic collections or collections generated by mass scraping.

The sole library with a clear policy in this regard is the Library of Congress. Information on the other institutions' policies was gleaned from indirect sources (the media) or by searching their collections.

Whilst the Bibliothèque Nationale de France provides no information on the subject, the other four institutions analysed (Library of Congress, British Library, National Library of Australia, Biblioteca Nacional de España) index memes in their web archives, normally as material in thematic collections. Given the social and testimonial value of such digital artefacts, that practice provides insight into the viral impact of certain headline-grabbing events, usually portrayed in a comical light (Figure 2).

[Insert Figure 2]

Figure 2. One of the memes archived by the Biblioteca Nacional de España after the Barcelona terrorist attacks (source: https://www.eldiario.es/rastreador/Biblioteca-Nacional-guardando-documental-)

In some cases (British Library, National Library of Australia), memes are embedded in websites indexed in collections on a specific topic, a social network such as Twitter or as the outcome of indirect scraping (as hashtags or part of tweets). In such cases the results are limited by collection depth and often confined to the domain scale, retrieving sites listing memes (such as Know Your Meme) but not the memes themselves. That is due in part to the technical shortcomings of crawlers that often archive multimedia content erroneously or incompletely.

The American Folklife Center's Web Cultures Web Archive is where the Library of Congress defines memes as independent units of digital culture expression. As the collection was built in conjunction with scholars studying that new culture, the selection lists websites that can accurately document the new forms of expression comprising what is known as vernacular language, including gifs, memes and emojis, as well as sites associated with anything from the DIY (do-it-yourself) movement to scary lore such as Creepypasta (Figure 3).

[Insert Figure 3]

Figure 3. Web Cultures Web Archive (source: https://www.loc.gov/collections/web-cultures-web-archive/about-thiscollection/)

For this collection, the Library of Congress is conducting an experimental data mining project in which users may participate to download, reuse or query collection content. In these files, memes are processed individually and deemed a unique documentary unit. That enables the 
library to generate lists of specific memes found on sites such as Meme Generator, indexed in the collection using Philosoraptor, Insanity Wolf or other templates in widespread use. The output of that individualised processing is a CSV file in which the images and data collected are translated into a minimal suite of metadata for identification, including the meme's ID code in the database, the URL of the page archived, the Meme Generator URL, the template used to create the meme, the size and MD5 code and a textual transcription of the meme. With its open dataset policy, the library seeks to document this representative element of today's digital culture in greater detail, while also encouraging societal reuse of the websites archived. The LC envisages more projects of this type in future in light of the interest aroused by research on web culture. Parts of both the Library of Congress's and the National Library of Australia's collections can be accessed with the libraries' metasearch engines. The British Library's collection can be accessed on the UKWA website. Access in the Bibliothèque Nationale de France and the Biblioteca Nacional de España is confined to terminals installed in the institutions themselves, pursuant to national legislation on intellectual property.

Of the three libraries offering virtual access to the collections, the Library of Congress and the British Library permit searches for any term or specific URL. Search results can then be clustered by domain and sub-domain, specific topic, availability, accessibility, document type and date. The National Library of Australia allows access to memes from its catalogue, filtering by domain, date and format.

\section{Discussion}

The aforementioned findings afford an overview of how today's digital culture is being archived by a number of heritage institutions. In connection with RQ1, the audiovisual micronarratives known as memes are deemed by those institutions to be a possible source of primary information that should consequently be collected and preserved for researchers in the future. At least four of the national libraries analysed (in United States, United Kingdom, Australia and Spain) include memes in their web archives. That fact is in keeping with an incipient concern in the literature around the need to preserve these dynamic cultural objects to ensure they will be accessible to future researchers (Tangherlini, 2016; McGowan, undated).

The strategies and practices followed (RQ2), however, differ from one institution to another in terms of coverage, archiving practice and processing. The Library of Congress is the sole organisation that deems memes to constitute a specific documentary type. The justification for building collections of these artefacts is their connection with digital folklore created in and communicated across new social platforms. As they have been built in keeping with the criteria of new digital culture scholars, the resulting selection includes websites that can accurately document the new forms of expression known as (digital) vernacular language, such as gifs, memes and emojis, as well as sites carrying content ranging from the DIY movement to horror fiction. The other three (British, Australian, Spanish) libraries furnishing information in this regard list memes tangentially either as content embedded in other materials such as tweets or to illustrate documents contained in thematic collections (elections, political campaigns...). In the British and Australian collections memes are embedded normally in social media or memegenerating websites bearing the national domain.

Access to these collections still poses many challenges for the institutions concerned. The first is accessibility-related, for in some cases the information can only be queried from facilities on library premises. The second revolves around satisfactorily curating their content to ensure 
objects can be retrieved from the catalogue together with all the context required by researchers in the future to understand their signifiers and meanings.

Recreating the context in which memes are generated and viralised and the mechanisms involved in their reproduction entails technical difficulties. Memes involve highly intertextual discourse, with one building one on top of another (Milner, 2012). As a result of such intertextual power, these artefacts become objects of mass culture that transcends the internet universe. In some cases advertising campaigns have been orchestrated around their popularity. Recontextualisation differences hamper object processing for preservation purposes, however.

In response to RQ3, technical meme processing by heritage institutions is still embryonic. Technical difficulties and the characteristics inherent in these artefacts encumber strategies for their user-friendly description and archiving. The Library of Congress's data mining project to index memes and gifs included in thematic collections merits mention in this context. The implementation of such projects is related to growing researcher interest in today's digital culture and above all to the need to ensure these objects' reusability. More than mere static access to a specific obsolete website, researchers need to be able to explore and reuse the datasets in question.

All these challenges justify the preservation of ephemeral digital culture as an area of promise for future generations of researchers.

\section{Conclusions}

This article explores the strategies for conserving and preserving memes implemented by a sampling of some of the world's major heritage institutions. It identifies the lines of action but also the absence of policies for building collections of these artefacts so representative of today's mass culture.

As noted in the introduction, as information units and signifiers, memes and gifs convey meaning quite beyond their apparent triviality. They also mirror current social and cultural mores. That capacity, together with their power of communication, is often addressed in the academic literature. This article is deemed to pioneer the study of their preservation in light of the paucity of precedents, describing how these artefacts are indexed by a number of heritage institutions entrusted with safeguarding the digital heritage.

The findings identify a series of issues that merit consideration. Firstly, as a fairly recent development, memes are not yet the object of specific selection and conservation criteria. The scant explanations provided by the institutions studied about collection practice are couched in terms of their interest as part of web culture and digital folklore. Tangherlini (2016) contends that the web and especially the social web is a self-organised, dynamic archive of folklore. Archiving collections containing such a diversity of data, of which memes are but one, is a challenge. With the paradigmatic exception of the Library of Congress, little or no information is to be found on how these audiovisual objects are archived. As a rule, the procedure is subject to the same crawling criteria as applied to archiving websites, with memes stored as screenshots downloaded from their repositories (e.g., Know Your Meme, Cuanto cabrón). Automatic selection as presently conducted, however, entails the loss of the backdrop against which they are produced and reproduced.

Secondly, in light of the role played by memes in conveying current information and their power of communication, libraries should adopt urgent measures to establish more precise guidelines for their preservation in web archives. The doubly ephemeral nature of these artefacts, stemming from the volatility of both content and media, poses a challenge for the institutions responsible for conserving this realm of the collective memory. 
Big Data era computational technology helps process massive amounts of information. With these mechanisms digital objects can be individualised and hidden patterns discovered to characterise the expressions of digital folklore, ushering in new, formerly unimaginable areas of social media research (Tangherlini, 2016). That notwithstanding, given that all the information in the internet universe is impossible to assimilate, the authors deem pre-crawling human intervention to be essential to process these collections. That is of particular importance for memes, where meaning and communicational potential are closely associated with the context in which they are created. Information professionals must therefore play the gatekeeper role, establishing criteria to guide the validity, importance and rationality of such archivist activity. The resulting collections, co-selected by documentation and information professionals and specialists in the respective fields, will help future generations of researchers understand how we relate to one another, how we process information and the events that prompt our indignation or our laughter.

As memes occupy more and more space in our everyday lives and broaden their scope of action (to marketing, social demands and new cultural and leisure habits), more research is called for on their conservation and processing. This study constitutes a valuable first foray into that line of research.

\section{References}

Bauman, Z. (2013). Liquid modernity. Cambridge: Polity Press

Bruns, A. and Weller, K. (2016) Twitter as a first draft of the present: and the challenges of preserving it for the future. In Proceedings of the 8th ACM Conference on Web Science, pp. 183189

Dawkins, R. (1976) The selfish gene. Oxford: Oxford University Press

Digital Preservation Coalition (DPC). (2009) Introduction to Digital Preservation Handbook. London: Digital Preservation Coalition. https://www.dpconline.org/handbook (accessed 26 June 2019).

García-Avilés, J. A., and Robles, F. A. (2016). Géneros periodísticos en los formatos visuales de Twitter: una propuesta de tipología. Textual \& visual media, 9: 101-132.

García- López, F. and Martínez-Cardama, S (2019). Micronarrativas audiovisuales como documento efímero: ¿quién archiva Internet?. In IV Simposio Internacional de Gestión de Comunicación. Comunicación, Medios, Industrias Creativas y Emprendimiento en la Era Digital. XESCOM, Porto, 25-27 April.

Gil, F. (2018) La Biblioteca Nacional está guardando memes por su valor documental para el future. El Diario.es. Available at https://www.eldiario.es/rastreador/Biblioteca-Nacionalguardando-documental-futuro 6 795180489.html (accessed 26 June 2019).

González, A and González, A. (2013) Memes, Rage Comics y Memenautas: comunicación efectiva en internet . Master thesis, Universidad Nacional de Educación a Distancia, ES.

Higgins, S. (2018). Digital curation: the development of a discipline within information science. Journal of Documentation, 74(6): 1318-1338.

Jenkins, H. (2003). Transmedia Storytelling: Moving characters from books to films to video games can make them stronger and more compelling. Technology Review. Available at http://www.technologyreview.com/Biotech/13052/?a=f (accessed 26 June 2019) 
Knobel, M. and Lankshear, C. (2007). Online memes, affinities, and cultural production. A new literacies sampler, 29: 199-227.

Martínez-Rolán, X. and Piñeiro-Otero, T. (2016) The use of memes in the discourse of political parties on Twitter: analysing the 2015 state of the nation debate. Communication \& Society, 29(1): 145-159 DOI: 10.15581/003.29.1.145-159

Mayagoitia, A. and González-Aguilar, J. (2017) "Internet Archive": la conservación de lo efímero. Documentación de las Ciencias de la Información, 40: 157-166

McGowan, C (s.f.) Digitally Born Folklore and Internet Archives: Where the Memes Have No Name. Available

at

http://catherinemcgowanthinks.com/img/McGowan TermPaper DigitalBornFolkloreandlnter netArchives.pdf (accessed 26 June 2019).

Milner, R. M. (2012) The World Made Meme: Discourse and identity in participatory media. Charleston: University of Kansas.

Moody-Ramirez, M. and Church, A. B. (2019) Analysis of Facebook Meme Groups Used During the 2016 US Presidential Election. Social Media+ Society, 5(1) DOI: $10.1177 / 2056305118808799$

Nichols, J. (2018). Revitalizing Language Learning: Using Media for Visual Story Experiences (Doctoral dissertation, UC San Diego). Available at https://escholarship.org/uc/item/800572m8 (accessed 26 June 2019)

Pemberton, J. (1971) The national provision of printed ephemera in the social sciences. Coventry: University of Warwick.

Shifman, L. (2012) An anatomy of a YouTube meme. New Media Society 4 (2) DOI: $\underline{10.1177 / 1461444811412160}$

Shifman, L. (2013). Memes in a Digital World: Reconciling with a Conceptual Troublemaker, Journal of Computer-Mediated Communication, 18 (3): 362377, https://doi.org/10.1111/jcc4.12013

Shifman, L. (2014) Memes in digital culture. Cambridge, MA: MIT Press.

Tangherlini, T. R. (2016) Big Folklore: A Special issue on computational Folkloristics. Journal of American Folklore, 129 (511): 5-13.

Turner, J. (1996). The dictionary of art. London: Grove. 